\title{
Effect of Heat Treatment on the Microstructure and Mechanical Properties of Nitrogen-Alloyed High-Mn Austenitic Hot Work Die Steel
}

\author{
Yi Zhang, Jing Li *, Cheng-Bin Shi, Yong-Feng Qi and Qin-Tian Zhu
}

State Key Laboratory of Advanced Metallurgy, University of Science and Technology Beijing (USTB), Beijing 100083, China; 15801455355@163.com (Y.Z.); shicb09@163.com (C.-B.S.); yongfeng_qi@126.com (Y.-F.Q.); zqtustb@163.com (Q.-T.Z.)

* Correspondence: lijing@ustb.edu.cn; Tel.: +86-189-1108-2675

Academic Editor: Robert Tuttle

Received: 27 January 2017; Accepted: 10 March 2017; Published: 14 March 2017

\begin{abstract}
In view of the requirements for mechanical properties and service life above $650{ }^{\circ} \mathrm{C}$, a high-Mn austenitic hot work die steel, instead of traditional martensitic hot work die steel such as H13, was developed in the present study. The effect of heat treatment on the microstructure and mechanical properties of the newly developed work die steel was studied. The results show that the microstructure of the high-Mn as-cast electroslag remelting (ESR) ingot is composed of $\gamma$-Fe, $\mathrm{V}(\mathrm{C}, \mathrm{N})$, and $\mathrm{Mo}_{2} \mathrm{C} . \mathrm{V}(\mathrm{C}, \mathrm{N})$ is an irregular multilateral strip or slice shape with severe angles. Most eutectic $\mathrm{Mo}_{2} \mathrm{C}$ carbides are lamellar fish-skeleton-like, except for a few that are rod-shaped. With increasing solid solution time and temperature, the increased hardness caused by solid solution strengthening exceeds the effect of decreased hardness caused by grain size growth, but this trend is reversed later. As a result, the hardness of specimens after various solid solution heat treatments increases first and then decreases. The optimal combination of hardness and austenitic grain size can be obtained by soaking for $2 \mathrm{~h}$ at $1170{ }^{\circ} \mathrm{C}$. The maximum Rockwell hardness (HRC) is $47.24 \mathrm{HRC}$, and the corresponding austenite average grain size is $58.4 \mu \mathrm{m}$. When the solid solution time is $3 \mathrm{~h}$ at $1230^{\circ} \mathrm{C}$, bimodality presented in the histogram of the austenite grain size as a result of further progress in secondary recrystallization. Compared with the single-stage aging, the maximum impact energy of the specimen after two-stage aging heat treatment was reached at $16.2 \mathrm{~J}$ and increased by $29.6 \%$, while the hardness decreased by 1-2 HRC. After two-stage aging heat treatment, the hardness of steel reached the requirements of superior grade H13, and the maximum impact energy was $19.6 \%$ higher than that of superior grade H13, as specified in NADCA\#207-2003.
\end{abstract}

Keywords: austenite hot work die steel; heat treatment; microstructure; mechanical properties; nitrogen

\section{Introduction}

In recent years, with the development of manufacturing industry and advanced metal materials, the working conditions of tools and dies become increasingly severer. The problem of raising service temperatures of high-load tools for hot deformation of metals and extending their service life will remain current for as long as this kind of process exists in metal treatment. This problem is especially difficult to solve when the working surface of the tool is heated to $700-900{ }^{\circ} \mathrm{C}$ or higher temperatures. Current commercial martensitic die steels such as AISI H13 and AISI H21—which are widely used for hot extrusion dies, forging dies, and casting dies-have a limited working capacity above a working temperature of $650{ }^{\circ} \mathrm{C}$ because of the decreasing strength [1]. The impossibility to overcome such a barrier is explainable by the occurrence of a polymorphic $\alpha \rightarrow \gamma$ transformation in these steels, which 
limits their service temperature [2]. It would be natural to assume that die materials-which do not possess the mentioned barrier within the service temperature range and have a strength exceeding that of highly heat-resistant martensitic steels at a temperature exceeding $700{ }^{\circ} \mathrm{C}$-should have an austenitic structure or belong to high-temperature alloys. Due to the high production cost of high-temperature alloys, highly heat-resistant austenitic steels may have good research and application prospects.

In contrast with martensitic hot work die steel, austenitic hot work die steel has no matrix phase transformation and is strengthened by precipitation hardening with various intermetallics, carbides, and nitrides [3]. The heat treatment gives austenitic steel excellent strength at elevated temperatures. In particular, when the temperature exceeds $650{ }^{\circ} \mathrm{C}$, the strength of austenitic hot work die steel is much higher than that of martensitic type. Another effective method for increasing steel quality is alloying with nitrogen. It has been pointed out that the addition of an appropriate amount of nitrogen can control the amount of carbonitrides and the austenite grain size to improve the mechanical properties [4]. The addition of nitrogen in steel, even in small quantities, makes it possible to obtain highly complex properties, such as strength, impact elasticity, and corrosion resistance. In addition, nitrogen is an effective and economic substitute for some expensive elements: nickel, manganese, molybdenum, and tungsten. According to these characteristics, high-nitrogen steels, especially high-nitrogen austenitic stainless steels, have been studied intensively in recent years [5-7]. In addition, it also reported that the effects of nitrogen element increase the impact toughness of steel and high-temperature strength of hot work die steels [8-10].

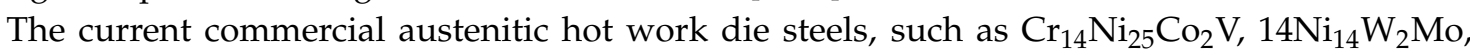
$5 \mathrm{Mn}_{15} \mathrm{Cr}_{8} \mathrm{Ni}_{25} \mathrm{Mo}_{3} \mathrm{~V}, \mathrm{Mn}_{10} \mathrm{Cr}_{8} \mathrm{Ni}_{10} \mathrm{Mo}_{3} \mathrm{~V}$, and $\mathrm{Mn}_{15} \mathrm{Cr}_{2} \mathrm{Al}_{3} \mathrm{~V}_{2} \mathrm{WMo}$, contain a large amount of alloying elements, leading to high steel production costs. In the present work, a new nitrogen-alloyed Fe- $\mathrm{Mn}-\mathrm{Cr}$ austenitic hot work die steel was developed by reducing $\mathrm{Cr}$, Ni, and Mo contents and adding a certain amount of nitrogen. The studies on the development of austenitic hot work die steel serving above the temperature of $650{ }^{\circ} \mathrm{C}$ have been rarely reported. Zhang et al. [11] reported that high manganese-vanadium austenitic steel, which is used for copper alloyed hot press die, has a great future in the development of hot work die steel used at a high temperature over $700{ }^{\circ} \mathrm{C}$. Grabovskii et al. [3] also reported that new austenitic alloys KhN35V6TYu (ÉK39) and KhN30VMYu (ÉK40) based on the Fe-Cr-Ni system can be recommended for manufacturing tools for hot deformation of metals serving at a temperature exceeding $700{ }^{\circ} \mathrm{C}$. In this study, the effect of heat treatment on the microstructures and mechanical properties in nitrogen-microalloyed high-Mn austenitic hot work die steel (HMAS-N) were examined first. An alternative hot work die steel—which is used for dies, needles, and washers-for the hot pressing of copper alloys is expected to serve above $700{ }^{\circ} \mathrm{C}$.

\section{Experimental Section}

\subsection{Experimental Materials}

HMAS-N steel was melted in a vacuum-induction furnace. Nitrogen-containing ferrochromium alloy was added in the smelting process. After vacuum-induction, the liquid steel was cast into the ingots of $120 \mathrm{~mm}$ diameter, which were thereafter used as consumable electrodes in electroslag remelting (ESR) experiments. The chemical composition of the steel is shown in Table 1. The experimental process includes forging, solid solution heat treatment (SSHT), and aging heat treatment. The as-cast ESR ingots were held at $1140{ }^{\circ} \mathrm{C}$ for $360 \mathrm{~min}$ and forged. The forging start and finish temperatures were $T_{S}=1200^{\circ} \mathrm{C}$ and $T_{f}=980^{\circ} \mathrm{C}$. The ESR ingot was forged into a rod of $\varnothing 160 \mathrm{~mm} \times 170 \mathrm{~mm}$. For solid solution heat treatment and aging heat treatment, the specimens taken from forged sample were heat treated in an electric resistance furnace.

Table 1. Chemical composition of tested steel (mass \%).

\begin{tabular}{cccccccccc}
\hline $\mathbf{C}$ & $\mathbf{M n}$ & $\mathbf{C r}$ & $\mathbf{M o}$ & $\mathbf{V}$ & $\mathbf{S i}$ & $\mathbf{P}$ & $\mathbf{S}$ & $\mathbf{N}$ & $\mathbf{F e}$ \\
\hline 0.56 & 14.5 & 3.192 & 1.641 & 1.723 & 0.52 & 0.015 & 0.029 & 0.15 & Bal. \\
\hline
\end{tabular}




\subsection{Microstructure and Precipitates of As-Cast ESR Ingot}

Thermo-Calc software (Thermo-Calc Software Inc., Solna, Sweden) was used to investigate phase equilibrium diagrams and identify the chemistry of various precipitates at different temperatures. The specimens were subjected to grinding, polishing, and etching. The microstructure and precipitates in these specimens were analyzed by scanning electron microscope (SEM, FEI Quanta-250, FEI Corporation, Hillsboro, OR, USA) equipped with energy-dispersive X-ray spectrometer (EDS, Xflash 5030, Bruker, Germany). The specimens taken from ESR ingots were machined to a bar of $\varnothing 15 \mathrm{~mm} \times 80 \mathrm{~mm}$. The precipitates were electrolytically extracted from steel in organic solution (methanol, tetramethylammonium chloride, glycerin, diethanol amine). The collected precipitates were analyzed using XRD (Rigaku Dmax-RB, Rigaku, Tokyo, Japan) technique to determine their types, and observed by SEM.

\subsection{Solid Solution Heat Treatment}

The specimens of the HMAS-N were solid solution treated at the temperatures of $1170{ }^{\circ} \mathrm{C}, 1200^{\circ} \mathrm{C}$, and $1230^{\circ} \mathrm{C}$ for $0.5,1,2$, and $3 \mathrm{~h}$. Thereafter, the specimens were quenched in water, and prepared for optical microscope (Leica DM4M, Leica Microsystems, Wetzlar, Germany) analysis. The average grain size was determined by the standard linear intercept method [12] through SISC IAS V8.0 image software [13]. About 400 austenite grains were selected randomly for the grain size measurement in each specimen. After various SSHT processes, the specimens were subjected to the same aging heat treatment at $720^{\circ} \mathrm{C}$ for $2 \mathrm{~h}$. Then, the specimens' Rockwell hardness values were measured.

\subsection{Aging Heat Treatment}

The optimum SSHT process can be selected by the above experimental scheme. After the specimens were subjected to the optimum SSHT, the following two kinds of aging heat treatments (single-stage aging and two-stage aging) were carried out. Single-stage aging and two-stage aging schemes are shown in Tables 2 and 3, respectively. For single-stage aging, the specimens, after optimal SSHT, were subjected to an aging heat treatment at $680-760{ }^{\circ} \mathrm{C}$ for $2 \mathrm{~h}$. For two-stage aging, the specimens, after optimal SSHT, were subjected to pre-aging treatment at $650{ }^{\circ} \mathrm{C}$ for $1 \mathrm{~h}$, and then re-aging was subsequently carried out in a temperature range from $700^{\circ} \mathrm{C}$ to $800^{\circ} \mathrm{C}$ for $1 \mathrm{~h}$.

Table 2. Single-stage aging heat treatment process after solid solution heat treatment (SSHT).

\begin{tabular}{ccc}
\hline The Specimen Number & Aging Temperature & Aging Time \\
\hline S-680 & $680^{\circ} \mathrm{C}$ & \\
S-700 & $700^{\circ} \mathrm{C}$ & \\
S-710 & $710^{\circ} \mathrm{C}$ & $2 \mathrm{~h}$ \\
S-720 & $720^{\circ} \mathrm{C}$ & \\
S-740 & $740^{\circ} \mathrm{C}$ & \\
S-760 & $760^{\circ} \mathrm{C}$ & \\
\hline
\end{tabular}

Table 3. Two-stage aging heat treatment process after SSHT.

\begin{tabular}{ccccc}
\hline $\begin{array}{c}\text { The Specimen } \\
\text { Number }\end{array}$ & $\begin{array}{c}\text { Pre-Aging } \\
\text { Temperature }\end{array}$ & $\begin{array}{c}\text { Pre-Aging } \\
\text { Time }\end{array}$ & $\begin{array}{c}\text { Re-Aging } \\
\text { Temperature }\end{array}$ & $\begin{array}{c}\text { Re-Aging } \\
\text { Time }\end{array}$ \\
\hline T-700 & & & $700^{\circ} \mathrm{C}$ & \\
T-720 & & $720^{\circ} \mathrm{C}$ & \\
T-740 & $650{ }^{\circ} \mathrm{C}$ & $1 \mathrm{~h}$ & $740^{\circ} \mathrm{C}$ & $1 \mathrm{~h}$ \\
T-760 & & & $760^{\circ} \mathrm{C}$ & \\
T-780 & & $780^{\circ} \mathrm{C}$ & \\
T-800 & & $800^{\circ} \mathrm{C}$ & \\
\hline
\end{tabular}




\subsection{Mechanical Properties}

The impact energy of specimens was tested at room temperature, using a JB-30B testing machine, with the Charpy V-notch test method according to ASTM 370 [14]. The value of impact energy presented in this paper is an average of three measurements. The Rockwell hardness (HRC) measurements with an applied load of $150 \mathrm{~kg}$ were performed on the heat-treated specimens. The average value of five tests for each specimen were recorded as the standard hardness.

\section{Results and Discussion}

\subsection{Precipitation and Microstructure of As-Cast ESR Ingot}

The equilibrium formation of precipitates in the studied steel was investigated using Thermo-Calc software (TCFE7 database). Figure 1 shows the relationship between the amount of precipitates and their precipitation temperatures in the temperature range from $600{ }^{\circ} \mathrm{C}$ to $1600{ }^{\circ} \mathrm{C}$. The transformation (precipitation) temperatures of precipitates in the investigated steel are listed in Table 4.

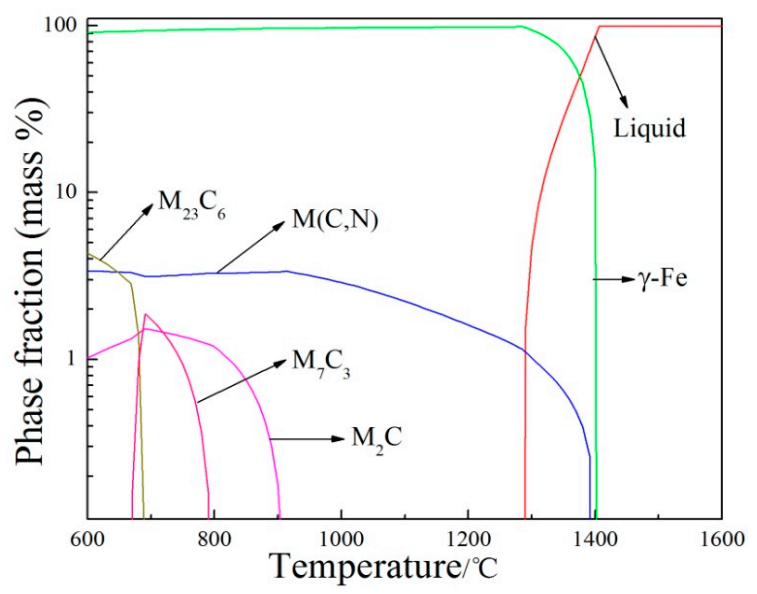

Figure 1. Equilibrium phase precipitations in nitrogen-microalloyed high-Mn austenitic hot work die steel (HMAS-N) calculated using Thermo-Calc (M represents metallic element atom; C represents carbon atom).

Table 4. Calculation results of transformation temperatures of precipitates in steel, calculated using Thermo-Calc.

\begin{tabular}{ccccccc}
\hline & \multicolumn{3}{c}{$T_{s} /{ }^{\circ} \mathrm{C}$} & \multicolumn{3}{c}{$T_{f} /{ }^{\circ} \mathrm{C}$} \\
\hline$\gamma-\mathrm{Fe}$ & $\mathrm{M}(\mathrm{C}, \mathrm{N})$ & $\mathrm{M}_{2} \mathrm{C}$ & $\mathrm{M}_{23} \mathrm{C}_{6}$ & $\mathrm{M}_{7} \mathrm{C}_{3}$ & $\mathrm{M}_{2} \mathrm{C}$ & $\mathrm{M}_{7} \mathrm{C}_{3}$ \\
1400 & 1392 & 910 & 690 & 790 & 435 & 670
\end{tabular}

$T_{s}$ represents phase transformation starting temperature, $T_{f}$ represents phase transformation finish temperature.

It can be seen from Figure 1 and Table 4 that $M(C, N), M_{2} C, M_{23} C_{6}$, and $M_{7} C_{3}$ precipitate in sequence with the decrease of temperature. The precipitation temperature of $M(C, N)$ is above $1300{ }^{\circ} \mathrm{C}$. This indicates that $\mathrm{M}(\mathrm{C}, \mathrm{N})$ is a highly stable phase and remains undissolved during heat treatment process.

To predict phase precipitation during liquid steel solidification in a practical ESR refining process, the Scheil-Gulliver model included in Thermo-Calc software was employed to calculate the nonequilibrium phase precipitation in HMAS-N, as shown in Figure 2. $M(C, N)$ precipitates from liquid steel directly. As the austenite continues to precipitate from liquid steel, carbon and alloying element contents keep increasing. Primary carbides $\mathrm{M}_{2} \mathrm{C}$ precipitate directly from liquid steel when the solid fraction of liquid steel exceeds 0.93. As shown in Figure 3a,b, partial primary carbides precipitate 
along preexisting austenite due to the composition of residual liquid steel reaching eutectic point. There are two types of precipitates (i.e., white- and gray-colored ones), which are represented by I and II, in as-cast ESR ingot as shown in Figure 4. The gray-colored and white-colored precipitates both distributed along grain boundaries. It can be seen in Figure 4 that some $\mathrm{M}(\mathrm{C}, \mathrm{N})$ carbonitrides are mixed with $\mathrm{M}_{2} \mathrm{C}$ carbides on the grain boundary. This is because the $\mathrm{M}(\mathrm{C}, \mathrm{N})$ phase precipitates at a higher temperature prior to the precipitation of the $\mathrm{M}_{2} \mathrm{C}$ phase.

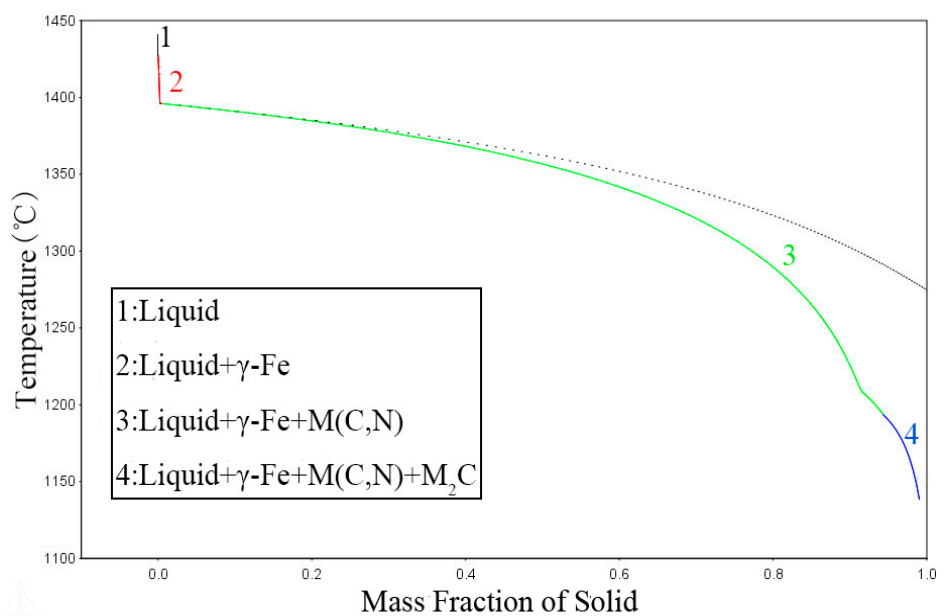

Figure 2. Nonequilibrium phase precipitation in HMAS-N, calculated using Thermo-Calc.
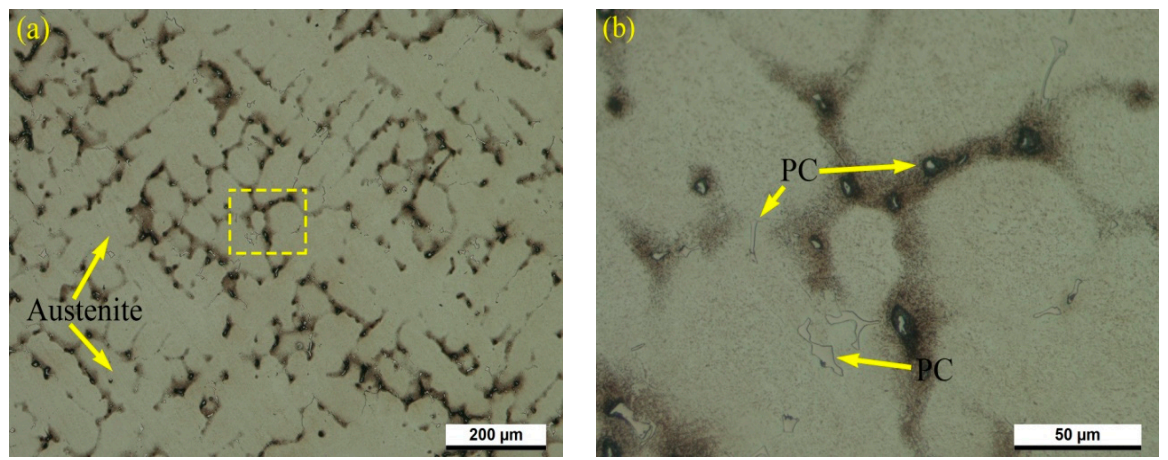

Figure 3. (a) Optical microscope (OM) images of as-cast electroslag remelting (ESR) ingot microstructure; (b) highly magnified images taken at the region marked by the yellow box in (a). PC represents primary carbides or carbonitrides.

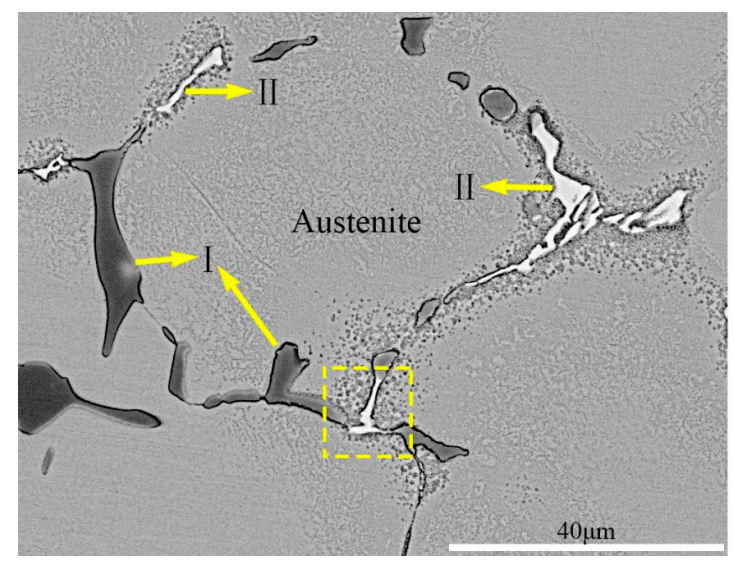

Figure 4. Scanning electron microscopy (SEM) images of as-cast ESR ingot microstructure. 
It can be confirmed from the microstructure in Figure 4 and the XRD results in Figure 6a that the matrix is a single austenite phase. Table 5 presents the EDS results of the carbides or carbonitrides shown in Figure 5. As shown in Table 5 and Figure $6 b, M(C, N)$ (namely $V(C, N)$ ) contains a certain amount of the elements $\mathrm{Cr}$ and Mo. In addition, $\mathrm{M}_{2} \mathrm{C}$ is $\mathrm{Mo}_{2} \mathrm{C}$, which contains more $\mathrm{Cr}$ and Mo atoms. As shown in Figure 5, the morphology of $\mathrm{V}(\mathrm{C}, \mathrm{N})$ is an irregular multilateral strip or slice shape with severe angles. The morphology of $\mathrm{Mo}_{2} \mathrm{C}$ is rod-shaped or lamellar fish-skeleton-like, which is typical eutectic carbide according to eutectic reaction $\left(\mathrm{L} \rightarrow \gamma+\mathrm{M}_{2} \mathrm{C}\right)$.

Table 5. Energy-dispersive X-ray spectrometer EDS analyzed results of carbides or carbonitrides (mass \%).

\begin{tabular}{cccccccc}
\hline \multirow{2}{*}{ Point } & \multicolumn{7}{c}{ Element } \\
\cline { 2 - 8 } & $\mathbf{C}$ & $\mathbf{V}$ & Mo & Cr & N & Fe & Mn \\
\hline 1 & 14.68 & 41.60 & 0.64 & 1.68 & 33.11 & 6.31 & 1.98 \\
2 & 56.69 & 6.88 & 17.35 & 7.94 & 0.05 & 5.55 & 5.54 \\
\hline
\end{tabular}

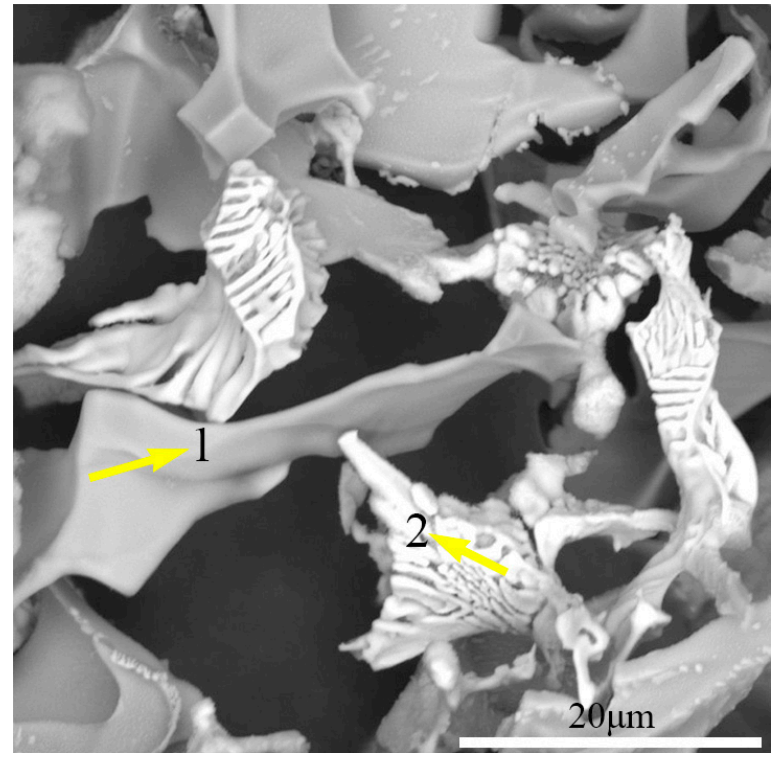

Figure 5. SEM micrographs showing the three-dimensional morphology of carbides or carbonitrides extracted from as-cast ESR ingot.
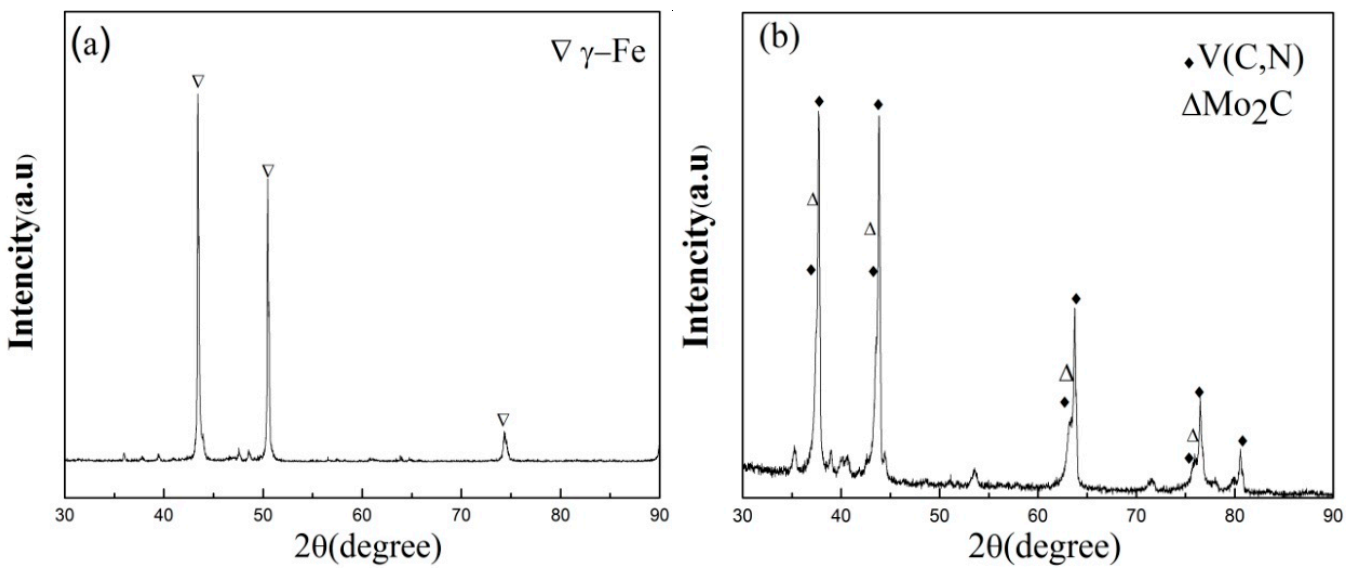

Figure 6. XRD patterns of steel block and precipitates powder: (a) steel block after etching of as-cast ESR ingot; (b) precipitate powders that were electrolytically extracted from as-cast ESR ingot. 


\subsection{Effect of Solid Solution Heat Treatment on Hardness and Microstructure}

Solid solution heat treatment (SSHT) was carried out to dissolve coarse primary precipitates in the matrix, which were then reprecipitated from supersaturated solid solution during the subsequent aging process with the purpose of precipitation strengthening. If the solution temperature is too low, large primary precipitates are difficult to dissolve into matrix. However, if the solid solution temperature is too high, austenitic grain size (AGS) will grow up excessively. The AGS tremendously influences diffusive and diffusionless phase transformations, precipitation, and mechanical properties such as strength, hardness, toughness, and ductility [15]. Hence, the SSHT process is quite important for microstructures and mechanical properties. The effects of SSHT on the austenite grain size, microstructure, and Rockwell hardness were studied in detailed.

The hardness value of the specimens, which were subjected to various SSHT and the same aging treatment at $720^{\circ} \mathrm{C}$ for $2 \mathrm{~h}$, is shown in Figure 7a. The hardness value increased from $45.34 \mathrm{HRC}$ to $47.24 \mathrm{HRC}$ at a solution temperature of $1170{ }^{\circ} \mathrm{C}$ with increasing solution time from $0.5 \mathrm{~h}$ to $2 \mathrm{~h}$. However, the hardness value decreased rapidly to $39 \mathrm{HRC}$ when the solid solution time was $3 \mathrm{~h}$ at $1170{ }^{\circ} \mathrm{C}$. When the solid solution temperature reached $1200{ }^{\circ} \mathrm{C}$ and $1230{ }^{\circ} \mathrm{C}$, the hardness decreased linearly with the increase of solution holding time from $0.5 \mathrm{~h}$ to $3 \mathrm{~h}$.
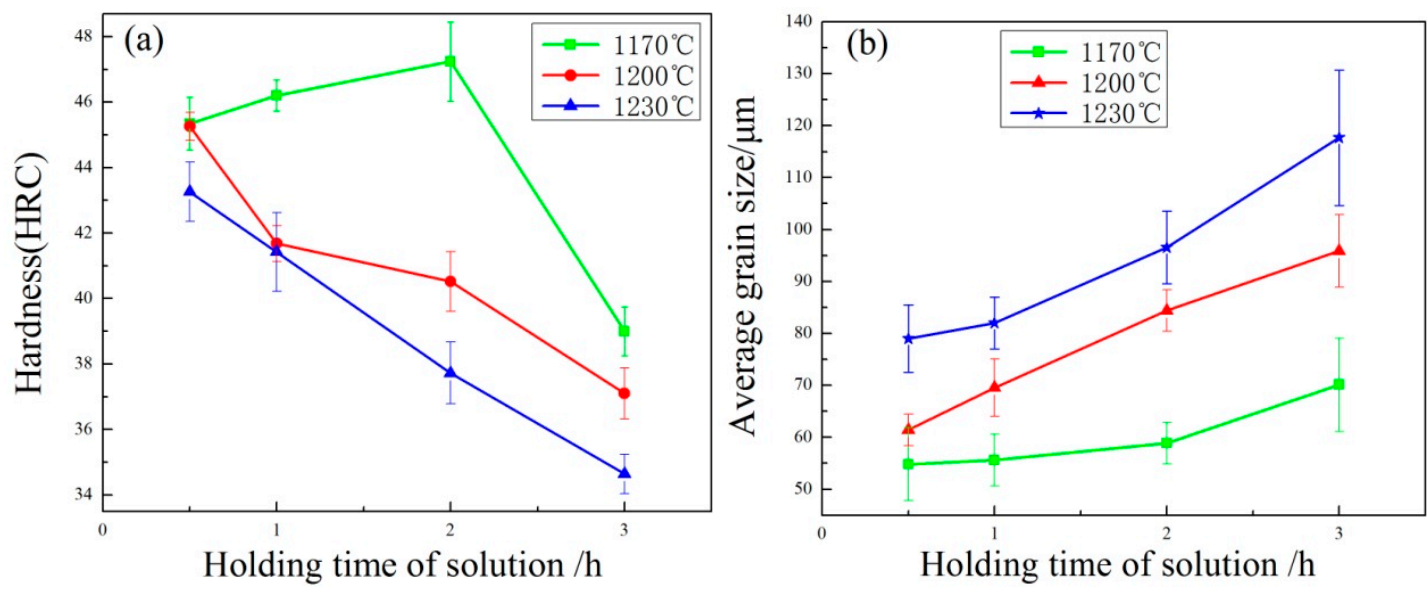

Figure 7. Rockwell hardness (a) and austenite average grain size (b) after various holding time at different solution temperatures.

The AGS after different solution heat treatments is shown in Figure $7 \mathrm{~b}$. The austenite grain grew gradually with increasing solution temperature and solution time. The austenite grains grew slowly at a solution temperature below $1200{ }^{\circ} \mathrm{C}$. A tangible grain growth was detected at $1170{ }^{\circ} \mathrm{C}$ for soaking times over $3 \mathrm{~h}$ due to the coupled effects of the soaking time and temperature on the grain growth. The results presented in Figure $7 \mathrm{~b}$ also implied that the effect of solution temperature on grain growth was more noticeable than solution time.

Figures 8 and 9 show the microstructure evolution at different solution temperatures and solution times with corresponding austenitic grain-size distribution histograms, respectively. As shown in Figure 9, the grain size distribution of austenite is close to lognormal distribution, which is consistent with the results presented by Han et al. [16] and Kurtz et al. [17]. When the solid solution time is $0.5 \mathrm{~h}$ at $1170{ }^{\circ} \mathrm{C}$, the fine austenite grains distribute inhomogeneously as coarse austenite grains and contact each other, as shown in Figure 8a. Figure 9a indicates the grain size of austenite is mainly in the range of $20-50 \mu \mathrm{m}$. The percentage of AGS smaller than $20 \mu \mathrm{m}$ is $14.9 \%$. When the specimens were solid solution treated at $1170{ }^{\circ} \mathrm{C}$ for an aging time between $0.5 \mathrm{~h}$ and $2 \mathrm{~h}$, AGS ranged from $54.8 \mu \mathrm{m}$ to $58.4 \mu \mathrm{m}$. No obvious grain growth was observed in Figure 8a,b. Those primary carbonitride particles that precipitated along grain boundaries affected the diffusion of iron and carbon atoms, and finally prevented the growth of austenite grain in the heating process $[15,18]$. Compared with the results 
shown in Figure 9a, AGS distributes more uniform after SSHT for $2 \mathrm{~h}$, as shown in Figure 9b. The grain size of austenite shown in Figure 9c was mostly in the range of 60-80 $\mu \mathrm{m}$, and the number of austenite grains larger than $50 \mu \mathrm{m}$ increased with rising solution temperature. When the solid solution time is $3 \mathrm{~h}$ at $1230{ }^{\circ} \mathrm{C}$, the bimodality of the histogram presented as a result of further progress in the second recrystallization, presented in Figure 9d.

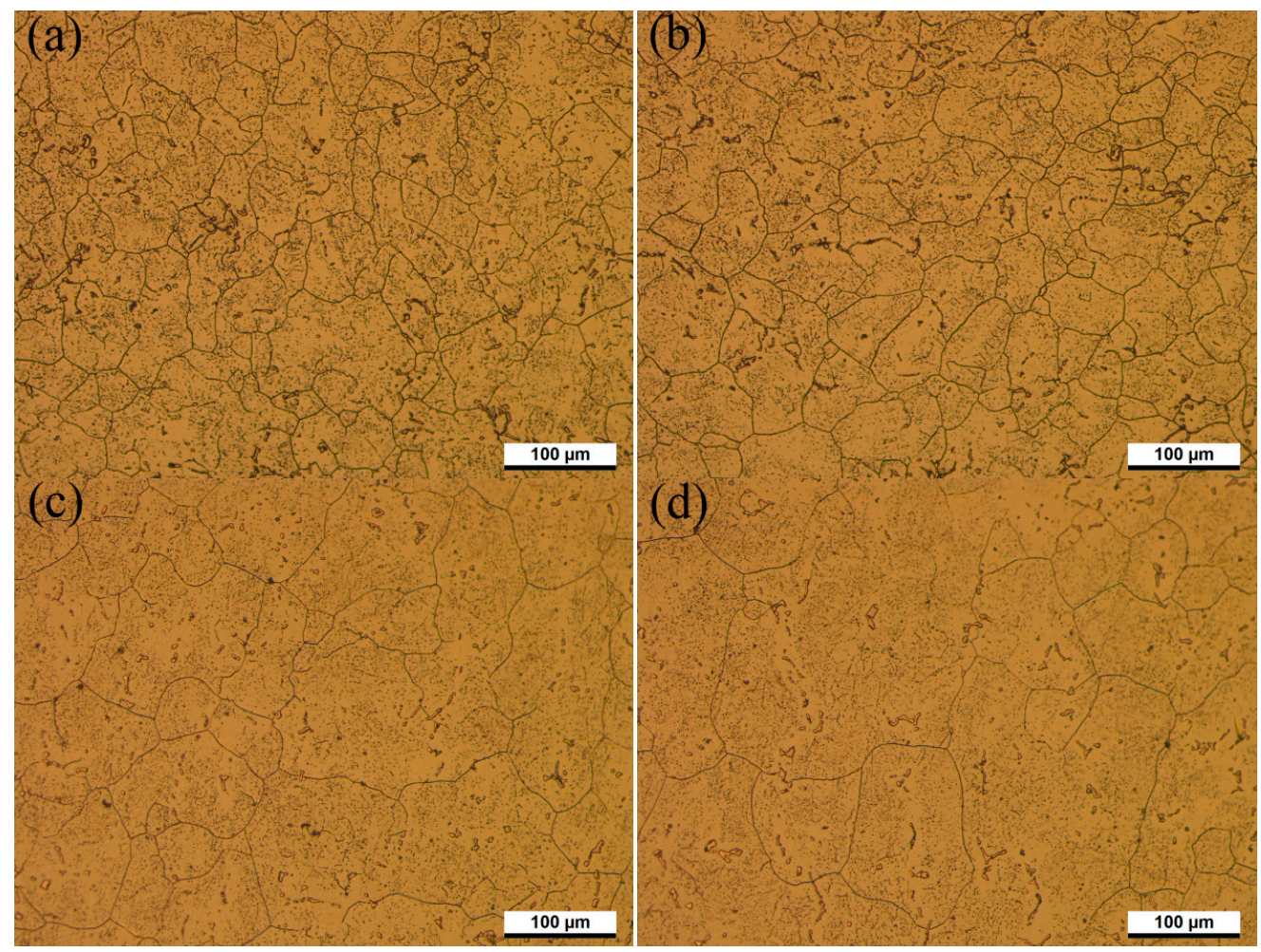

Figure 8. Effect of solution temperature and solution time on microstructure evolution at (a) $1170{ }^{\circ} \mathrm{C}$ for $0.5 \mathrm{~h}$; (b) $1170{ }^{\circ} \mathrm{C}$ for $2 \mathrm{~h}$; (c) $1200{ }^{\circ} \mathrm{C}$ for $2 \mathrm{~h}$; and (d) $1230{ }^{\circ} \mathrm{C}$ for $3 \mathrm{~h}$.

As shown in Figure 8a, the precipitates were not completely dissolved at $1170{ }^{\circ} \mathrm{C}$, which is consistent with thermodynamic calculation using Thermo-Calc software. Thermodynamic calculation illustrates that precipitation temperature of the primary $\mathrm{V}(\mathrm{C}, \mathrm{N})$ reaches up to $1390{ }^{\circ} \mathrm{C}$, as shown in Table 4. $\mathrm{N}$ addition in steel increased the melting point and stability of carbonitrides. In addition, most primary $\mathrm{V}(\mathrm{C}, \mathrm{N})$ were distributed along the austenite grain boundary and were not significantly influenced by solution heat treatment [19]. Hence, primary $\mathrm{V}(\mathrm{C}, \mathrm{N})$ cannot completely dissolve into the matrix when the solution temperature is below $1390{ }^{\circ} \mathrm{C}$. Therefore, it can be concluded that the pinning effect of undissolved $\mathrm{V}(\mathrm{C}, \mathrm{N})$ [20] suppressed austenite grain growth with increasing solution time from $0.5 \mathrm{~h}$ to $2 \mathrm{~h}$ at $1170{ }^{\circ} \mathrm{C}$. Meanwhile, more carbides, carbonitrides, and alloying elements dissolved into the austenite matrix with increasing solid solution time at $1170{ }^{\circ} \mathrm{C}$. Owing to solution strengthening and the second phase strengthening during the process of aging heat treatment, the hardness of steel reached the maximum value at $2 \mathrm{~h}$ aging time when solution temperature was at $1170{ }^{\circ} \mathrm{C}$. When aging time exceeded $2 \mathrm{~h}$ at $1170^{\circ} \mathrm{C}$, the austenite grain grew rapidly, which led to the decrease of hardness value. When the solution temperature is more than $1170{ }^{\circ} \mathrm{C}$, the $\mathrm{AGS}$ grows rapidly, despite a significant amount of undissolved secondary phases. This is attributed to coagulation process during the SSHT process, leading to the growth of large particles at the expense of small ones and the reduction in the amount of precipitates. A small number of large precipitates do not limit grain boundary mobility, and pinning effects disappear [21]. Grain growth highly depends on the grain boundary migration and the atomic diffusion. Moreover, the dissolution/coarsening of precipitates occurs at higher temperatures [22,23]. Furthermore, the solute drag effect of alloying elements is not 
effective enough at very high temperatures due to their higher frequency of vibration and mobility [24]. Therefore, the grain growth kinetics is intensified by increasing solid solution temperature. At a very high solution temperature of $1230{ }^{\circ} \mathrm{C}$, the austenite grains coarsened significantly. The coarse austenite grains accelerated the development and growth of fatigue-induced cracks, which will lead to hot work steel failure. After solid solution at $1230{ }^{\circ} \mathrm{C}$ for $3 \mathrm{~h}$, grain coarsening became more evident as a result of further progress in the second recrystallization, shown in Figures $8 \mathrm{~d}$ and $9 \mathrm{~d}$. Hence, austenitic grain-coarsening speed is accelerated, and undissolved $\mathrm{V}(\mathrm{C}, \mathrm{N})$ pinning effect was weakened, resulting in the decrease of hardness in a linear trend when the solution temperature exceeds $1200{ }^{\circ} \mathrm{C}$. Hence, the optimal combination of hardness and AGS can be obtained by soaking for $2 \mathrm{~h}$ at $1170{ }^{\circ} \mathrm{C}$.
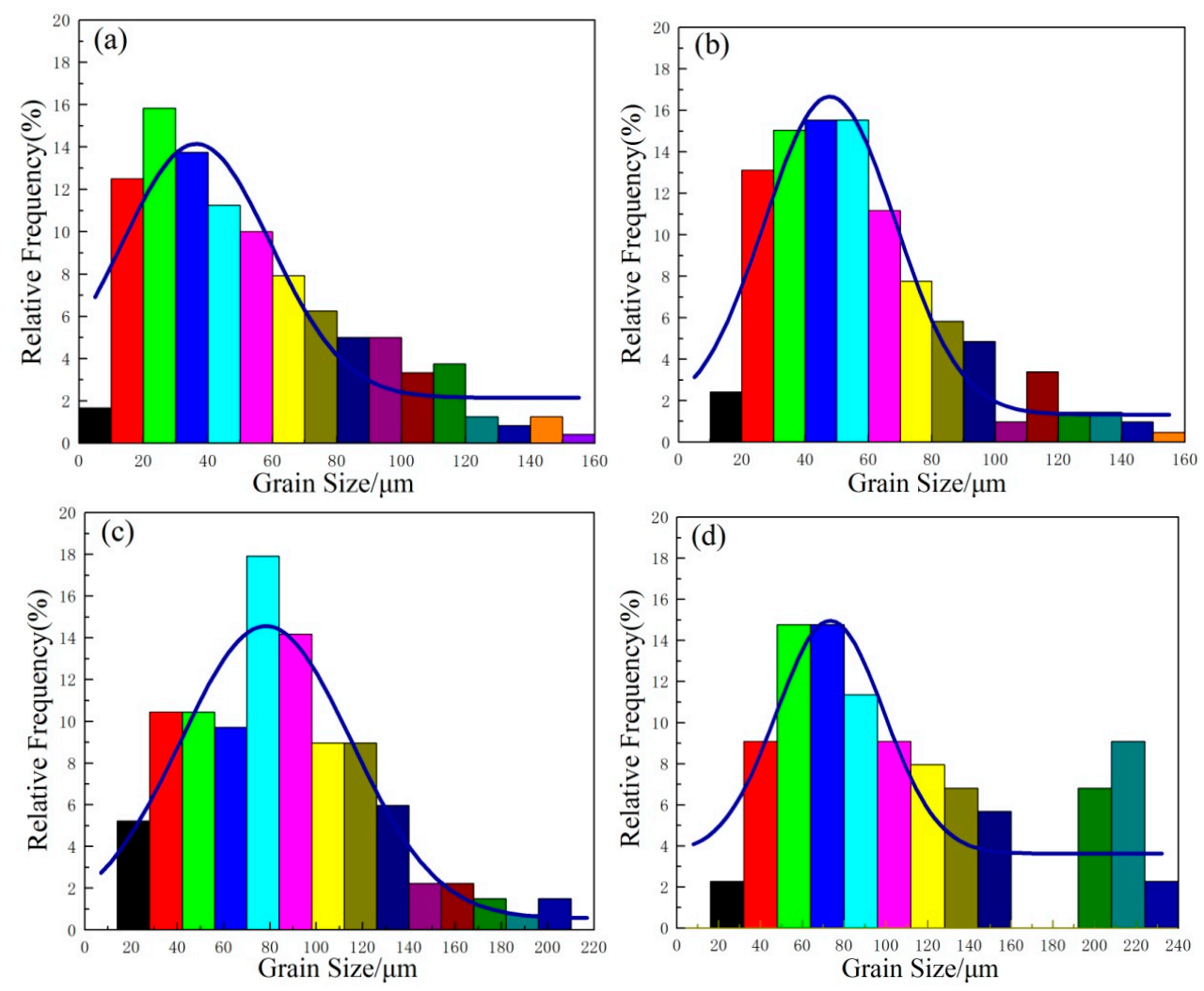

Figure 9. Grain-size distribution histograms obtained upon solution treatment at (a) $1170{ }^{\circ} \mathrm{C}$ for $0.5 \mathrm{~h}$; (b) $1170{ }^{\circ} \mathrm{C}$ for $2 \mathrm{~h}$; (c) $1200{ }^{\circ} \mathrm{C}$ for $2 \mathrm{~h}$; and (d) $1230{ }^{\circ} \mathrm{C}$ for $3 \mathrm{~h}$.

\subsection{Effect of Aging Heat Treatment on Mechanical Properties and Microstructure}

To remove residual stress caused by SSHT and dispersed small secondary phase particles, high-temperature aging heat treatment was carried out. The aging heat treatment process has a significant effect on comprehensive performance of HMAS-N. According to Grabovskii et al. and Lanskaya's [3,25] reports, two-stage aging instead of single-stage aging can substantially increase impact toughness at the same level of high-temperature strength, which positively affects the crack resistance of the tools and increases their service life. However, there are few literatures on the effect of multiple aging on the microstructure and properties of austenitic hot work die steels. Al- $\mathrm{Zn}-\mathrm{Mg}$ alloys and some high-temperature alloys such as iron-nickel superalloys are subjected to multistage aging to enhance their comprehensive performance [26,27]. To improve the comprehensive performance of HMAS-N, the effects of single-stage aging and two-stage aging on the microstructure and properties of steel were studied.

As for single-stage aging, experiments were carried out in a temperature range from $680{ }^{\circ} \mathrm{C}$ to $760^{\circ} \mathrm{C}$ for $2 \mathrm{~h}$, as shown in Table 2 . The hardness improves gradually with aging temperature increasing 
from $680^{\circ} \mathrm{C}$ to $720^{\circ} \mathrm{C}$, as shown in Figure 10. When the aging temperature was at $720^{\circ} \mathrm{C}$, significant secondary hardening occurred, and the hardness reached the maximum value of $47.24 \mathrm{HRC}$. It can be attributed to the enrichment and segregation of precipitate-forming elements at $720^{\circ} \mathrm{C}$, such as $\mathrm{V}$, Mo, $\mathrm{Cr}, \mathrm{C}$, and $\mathrm{N}$ [8]. As the aging temperature continued to increase, the hardness decreased to $45.04 \mathrm{HRC}$ at $760{ }^{\circ} \mathrm{C}$. As for the two-stage aging, pre-aging and re-aging heat treatment experiments were carried out, shown in Table 3. The hardness increases with the re-aging temperature increasing from $700{ }^{\circ} \mathrm{C}$ to $760{ }^{\circ} \mathrm{C}$. When the two-stage aging temperature was at $760^{\circ} \mathrm{C}$, the hardness reached the peak value of $46.06 \mathrm{HRC}$. As the re-aging temperature continued to increase, the hardness decreased and dropped to $43.84 \mathrm{HRC}$ at $800{ }^{\circ} \mathrm{C}$. Compared to single-stage aging, the hardness value of two-stage aging is slightly less than single-stage aging at the same aging temperature. In addition, the temperature for maximum hardness delayed. To ensure that the steel has higher hardness and impact toughness to restrain crack initiation and growth in the process of service, the Charpy impact tests were carried out for the specimens with Rockwell hardness values greater than $45 \mathrm{HRC}$ after aging heat treatment. The impact energies after different aging heat treatments are shown in Figure 11. For single-aging at $720^{\circ} \mathrm{C}$, the hardness value reached the maximum value of $47.24 \mathrm{HRC}$, whereas the impact energy reached the minimum value at $9.2 \mathrm{~J}$. The impact energy reached the maximum value of $12.5 \mathrm{~J}$ and the corresponding hardness value was $46.05 \mathrm{HRC}$ at $740{ }^{\circ} \mathrm{C}$. For two-stage aging, the impact energy gradually increased and reached the maximum value of $16.2 \mathrm{~J}$ at $780^{\circ} \mathrm{C}$ with increasing temperature from $740{ }^{\circ} \mathrm{C}$ to $780^{\circ} \mathrm{C}$. As for two-stage aging heat treatment, impact energy greatly improved despite the hardness decreasing by 1-2 HRC compared with single-stage aging.

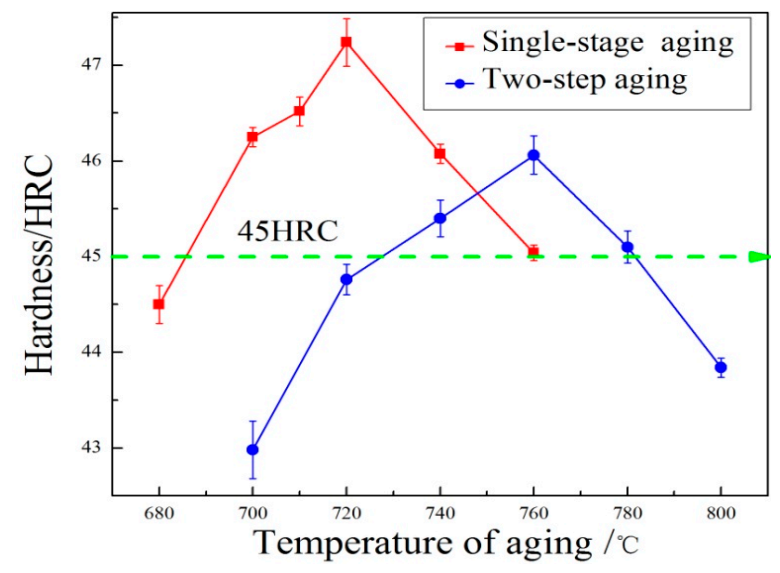

Figure 10. Hardness of specimens with different aging heat treatment processes.

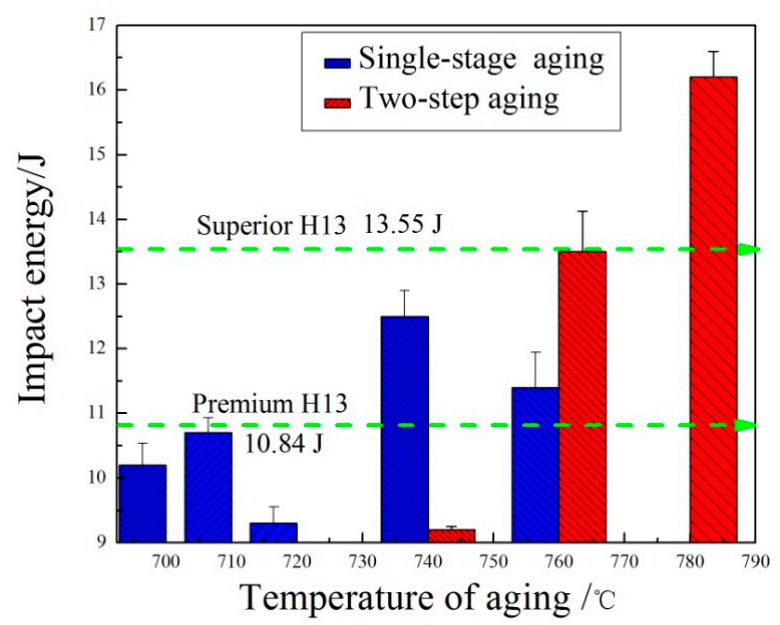

Figure 11. Impact energy of specimens aged with different aging heat treatment processes. 
The maximum impact energy value of $16.2 \mathrm{~J}$ is not only higher than premium H13 (10.84 J), but also almost exceeds superior H13 (13.55 J) [28]. The newly prepared HMAS-N, in terms of the toughness, is considerably outstanding when taking H13 mechanical properties into consideration. Compared with the maximum impact energy of single-stage aging, two-stage aging impact energy increased $29.6 \%$. Despite the lowest hardness value of $45.1 \mathrm{HRC}$ at $780{ }^{\circ} \mathrm{C}$ re-aging temperature, it still meets the service requirements of hot work steel. Hence, in order to improve the comprehensive performance and service life, the optimal aging process is re-aging at $780^{\circ} \mathrm{C}$.

It is well known that structure and fractograph of a specimen are related to the mechanisms involved in the fracture process. The microstructure determines the performance of the steel. Figure 12a is a SEM micrograph of specimen S-720 at low magnification. It can be seen that there are massive, undissolved primary precipitates. Figure $12 \mathrm{~b}-\mathrm{d}$ are the scanning electron micrographs of specimens S-720, S-740, and S-760 at high magnification, respectively. When the aging temperature increased from $720^{\circ} \mathrm{C}$ to $740{ }^{\circ} \mathrm{C}$, the number of fine dispersed secondary carbonitrides increased, as shown in Figure $12 \mathrm{~b}, \mathrm{c}$. As the aging temperature increased to $760{ }^{\circ} \mathrm{C}$, the number of secondary carbonitrides decreased, but the secondary carbonitrides appeared to be aggregated, and the grain boundary was widened, as shown in Figure 12d. This is attributed to growth of large particles at the expense of small ones, resulting in the reduction in the total number of particles. Precipitation of carbides along the grain boundary will result in deterioration of toughness, which can be attributed to the decrease of grain boundary cohesion.

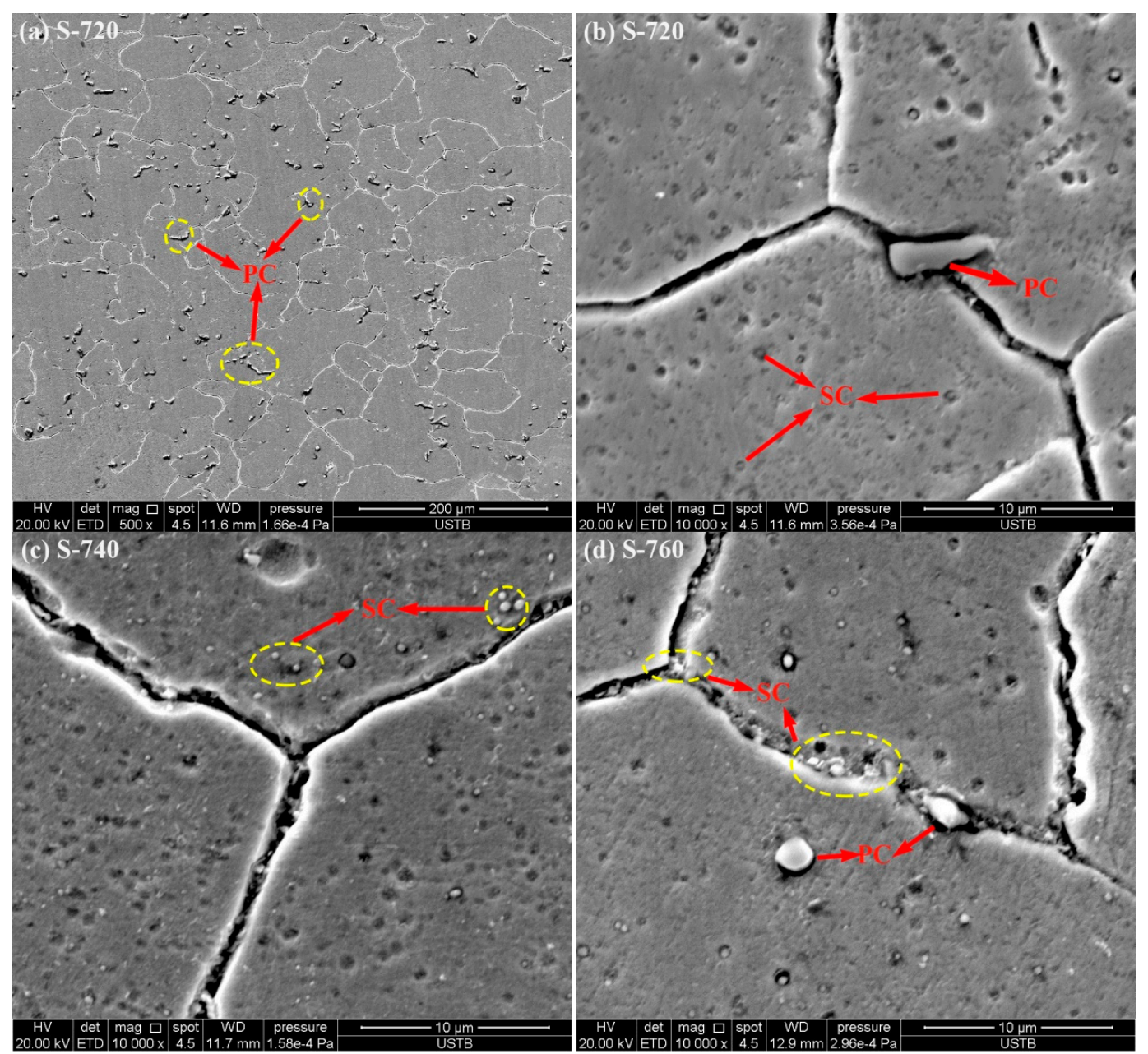

Figure 12. SEM microstructure of specimens after different aging heat treatment processes: (a,b) S-720, (c) S-740, (d) S-760. Note: PC represents primary precipitates. SC represents secondary precipitates. 
The SEM fractograph of specimens after the Charpy test for a fixed solid solution temperature $\left(1170{ }^{\circ} \mathrm{C}\right)$ and various aging processes are shown in Figure 13a-f. Both quasi-cleavage facets and ductile dimples were observed, which indicated the mixed mechanism of fracture. The specimen S-720 showed mainly brittle-fractured surface zones characterized by transgranular quasi-cleavage and intergranular fracture (Figure 13a). It can be noticed that quasi-cleavage fracture facets encircled by ridges are much smaller than the austenite grain $(58.4 \mu \mathrm{m})$, and this kind of morphology forms when a crack propagates along the primary precipitates. The size of intergranular fracture grains $(\sim 60 \mu \mathrm{m})$ was similar to the size of austenite grains $(58.4 \mu \mathrm{m})$. This implies that intergranular fracture along the boundaries of austenite grains operated partially for specimen S-720. As shown in Figure 13b, quasi-cleavage facets show massive primary precipitates, which is consistent with the observation in Figure 11a. It indicated that quasi-cleavage nucleated along the precipitates. Some portions of the fracture surface exhibited ductile-fractured surface with fine dimples (Figure 13c). The dimple percentage increases with increasing aging temperature (from $720^{\circ} \mathrm{C}$ to $760^{\circ} \mathrm{C}$ ) for single-stage aging treatment. The specimens S-740 and S-760 showed mainly ductile-fractured areas with fines dimples and some quasi-cleavage features (Figure 13d,e). It is clear that the fracture surface of specimen S-760 contained microcracks and some spherical secondary precipitates precipitated from the aging process, as shown in Figure 13e. The EDS results of the precipitates shown in Figure 13b,e are presented in Table 6. Figure 14 shows fractograph EDS element distribution mappings of specimen S-760. Figure 14 and the EDS results of point 1, shown in Figure 13b, indicate that elements N, V, C were enriched in the same area, confirming that undissolved coarse primary carbonitrides are $\mathrm{V}(\mathrm{C}, \mathrm{N})$, which also contains a small amount of Cr. Figure 14 and the EDS results of point 2, shown in Figure 13e, indicate that spherical secondary carbides are Mo-rich carbides. Specimen T-780 presented more ductile dimples and fewer quasi-cleavage facets (Figure 13f).

Table 6. The EDS results for precipitates (mass \%).

\begin{tabular}{cccccccc}
\hline \multirow{2}{*}{ Point } & \multicolumn{7}{c}{ Element } \\
\cline { 2 - 8 } & $\mathbf{C}$ & $\mathbf{V}$ & Mo & Cr & N & Fe & Mn \\
\hline 1 & 28.48 & 40.50 & 0.24 & 0.92 & 27.57 & 1.72 & 0.57 \\
2 & 37.07 & 0.26 & 16.57 & 1.65 & 0.00 & 43.62 & 0.83 \\
\hline
\end{tabular}

The undissolved primary precipitates, austenite grain size, strength of the matrix, secondary precipitates, and the strength of grain boundary have great effects on the impact energy, while aging heat treatment has little effect on primary precipitates and austenite grain size. For specimen S-720, the massive undissolved primary $\mathrm{V}(\mathrm{C}, \mathrm{N})$ had a higher hardness value $(47.2 \mathrm{HRC})$ and is not easy to deform, which is responsible for embrittlement for the lower impact energy ( $9.3 \mathrm{~J})$. A lower binding force among precipitates and steel matrix resulted from the existence of primary and secondary precipitates. It is much easier to generate cracks at the regions where primary $\mathrm{V}(\mathrm{C}, \mathrm{N})$ are enriched.

With increasing aging temperature from $720{ }^{\circ} \mathrm{C}$ to $740{ }^{\circ} \mathrm{C}$ for single-stage aging, the amount of secondary precipitates increased, which meant the interstitial atoms dissolved in the matrix precipitated and the degree of supersaturation decreased, resulting in the softening of the steel matrix [29]. The increasing number of secondary precipitates has a negative effect on impact energy. The softer the base metal, the larger the plastic district around the crack tip when the stress concentration is high enough and plastic deformation occurs. A larger plastic district will result in greater crack propagation and larger impact energy [30]. For specimen S-720 and S-740, the base metal plays the main role on impact energy compared to the negative effect of secondary precipitates. Hence, impact energy increased from $9.3 \mathrm{~J}$ to $12.5 \mathrm{~J}$ with increasing temperature, from $720{ }^{\circ} \mathrm{C}$ to $740{ }^{\circ} \mathrm{C}$, for single-stage aging temperature. When increasing temperature to $760^{\circ} \mathrm{C}$ for the single-stage aging, the amount of secondary precipitates increases and the coarsening of the austenite grain boundary has a major effect on the impact energy, which led to impact energy decreasing from $12.5 \mathrm{~J}$ to $11.4 \mathrm{~J}$.

For two-stage aging, the low-temperature pre-aging of the two-stage aging process is equivalent to the nucleation stage, and the high-temperature aging is the stabilization stage [26]. The first stage in 
aging of the alloy is to promote the formation of the GP (Guinier-Preston) zone, and then to obtain a large number of dispersed GP areas, and to make the GP areas extend to a certain scale without dissolution in the second stage of aging. In the second high-temperature aging process, the aging precipitation sequence of the alloy changes from GP zone to secondary precipitates, and the alloy enters the aging stage. This improves the working capacity of tools for hot deformation. The two-stage aging may be more conducive to distributed homogeneous precipitation of secondary precipitates and reducing growth of secondary precipitates, which will weaken the reduction of the impact energy compared to single-stage aging. As a result, the impact energy increases from $9.2 \mathrm{~J}$ to $16.2 \mathrm{~J}$ with a slight decrease of the strength when increasing the re-aging temperature from $740{ }^{\circ} \mathrm{C}$ to $780{ }^{\circ} \mathrm{C}$.

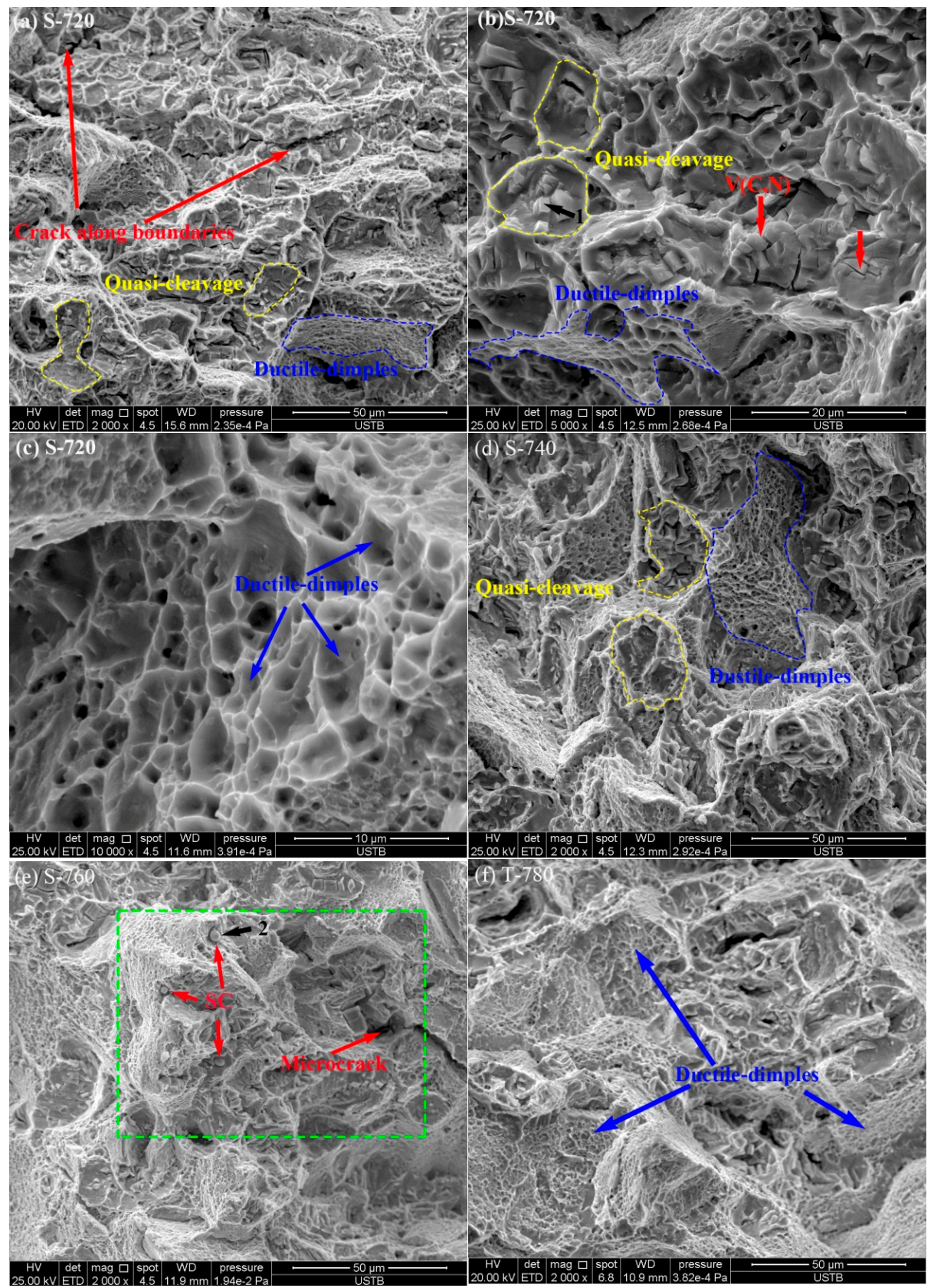

Figure 13. SEM fractographs of specimens after different aging heat treatment processes: (a-c) S-720; (d) S-740; (e) S-760; (f) T-780. (b) and (c) are highly magnified images taken at the region enriched with quasi-cleavage facets and dimples of specimen S-720, respectively. SC represents secondary precipitates. 

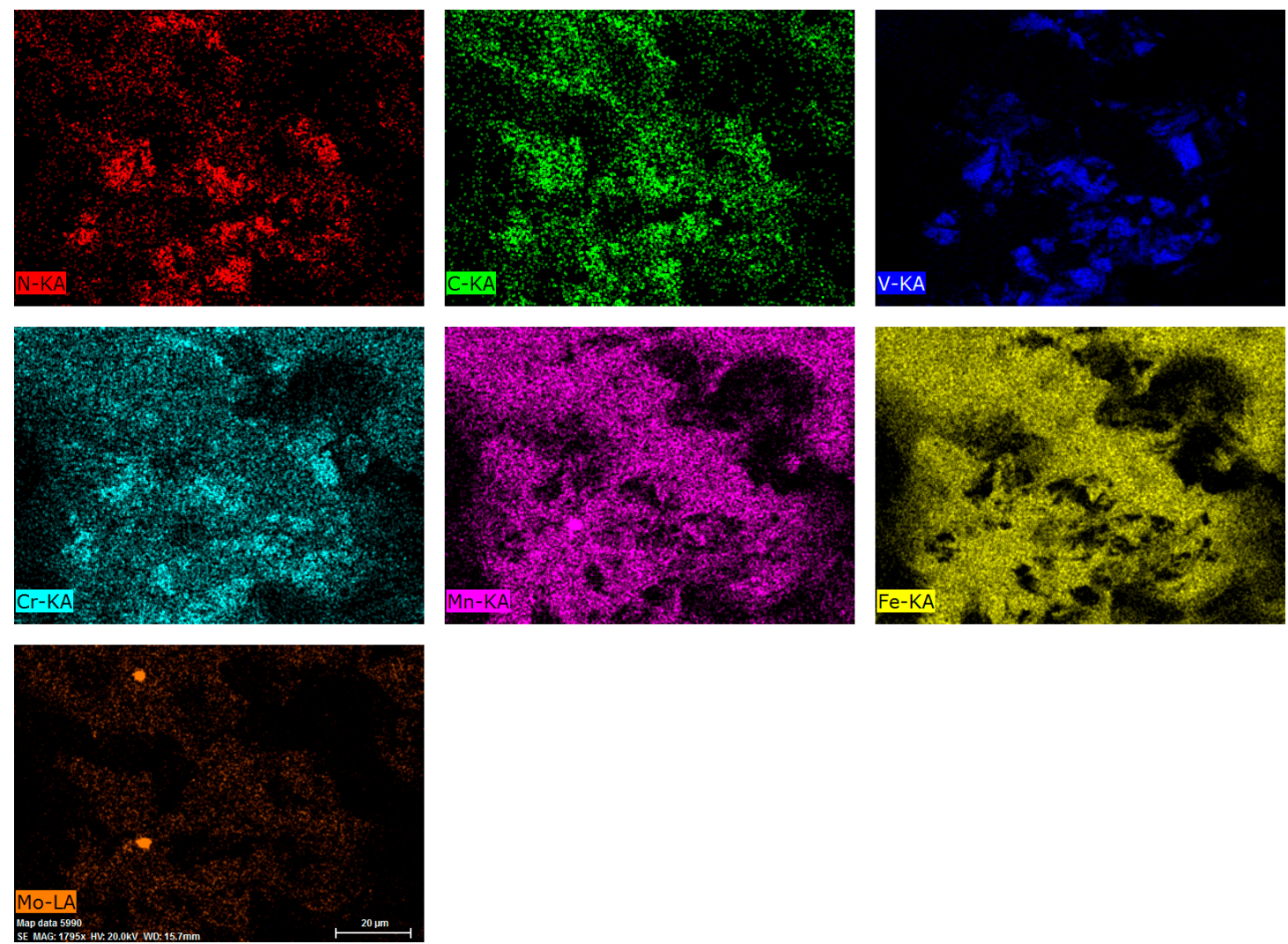

Figure 14. Energy-dispersive $X$-ray spectrometer (EDS) element mappings of S-760 fractograph, scale bar: $20 \mu \mathrm{m}$.

\section{Conclusions}

The microstructure of as-cast high-Mn ingot is composed of $\gamma$-Fe $+M(C, N)+M_{2} C \cdot M(C, N)$ precipitated from liquid steel directly, which is a highly stable phase. $\mathrm{M}(\mathrm{C}, \mathrm{N})$ is $\mathrm{V}(\mathrm{C}, \mathrm{N})$ containing $\mathrm{Cr}$, Mo elements. $\mathrm{M}_{2} \mathrm{C}$ is $\mathrm{Mo}_{2} \mathrm{C}$, containing more $\mathrm{Cr}$ and Mo elements, which formed by eutectic reaction ( $\mathrm{L} \rightarrow \gamma+\mathrm{M}_{2} \mathrm{C}$ ). The morphology of $\mathrm{V}(\mathrm{C}, \mathrm{N})$ is an irregular multilateral strip or slice shape with severe angles. Most of $\mathrm{Mo}_{2} \mathrm{C}$ morphology are lamellar fish-skeleton-like and a small number of $\mathrm{Mo}_{2} \mathrm{C}$ morphology are rod-shaped.

When increasing solid solution time from $0.5 \mathrm{~h}$ to $2 \mathrm{~h}$ at $1170{ }^{\circ} \mathrm{C}$, AGS ranges from $54.8 \mu \mathrm{m}$ to $58.4 \mu \mathrm{m}$ and no significant grain growth was observed, which can be attributed to the pinning effect of undissolved $\mathrm{V}(\mathrm{C}, \mathrm{N})$. Additionally, the hardness increased from 45.34 HRC to 47.24 HRC due to solid solution strengthening. When the solid solution temperature reached $1200{ }^{\circ} \mathrm{C}$ and $1230^{\circ} \mathrm{C}$, the effect of grain growth, which decreases hardness, exceeds the effect of solid solution strengthening, which increases hardness. The hardness value decreased linearly with the increase of solution temperature from $1200^{\circ} \mathrm{C}$ to $1230{ }^{\circ} \mathrm{C}$.

The AGS distribution of austenite is close to lognormal distribution. The austenite grains grew slowly at a solution temperature below $1200^{\circ} \mathrm{C}$. A tangible grain growth was detected at $1170{ }^{\circ} \mathrm{C}$ for soaking times over $3 \mathrm{~h}$ due to the synergic effect of the soaking time and temperature on the grain growth. When the solid solution time is $3 \mathrm{~h}$ at $1230^{\circ} \mathrm{C}$, the bimodality of histogram is presented as a result of further progress in secondary recrystallization.

For single-stage aging and two-stage aging, Rockwell hardness shows a trend of first increasing and then decreasing with increasing aging temperature. In addition, hardness reach the maximum at $740{ }^{\circ} \mathrm{C}(47.24 \mathrm{HRC})$ and $760^{\circ} \mathrm{C}(46.06 \mathrm{HRC})$, respectively, which is attributed to significant secondary 
hardening. Compared to single-stage aging, impact energy greatly improved despite the hardness decreasing by 1-2 HRC. In addition, the temperature for maximum hardness delayed.

Both quasi-cleavage facets and ductile dimples were observed in the fractograph, which indicates the mixed mechanisms of fracture. The two-stage aging may be more conducive to homogeneously distributed precipitation of secondary precipitates and reduced growing tendency of secondary precipitates, which will weaken the reduction of the impact energy compared to single-stage aging. Compared with the maximum impact energy of single-stage aging, maximum impact energy reached $16.2 \mathrm{~J}$ and increased by $29.6 \%$ when using two-stage aging. Thus, the optimum heat treatment process is subjected to solution treatment for $2 \mathrm{~h}$ at $1170{ }^{\circ} \mathrm{C}$, followed by pre-aging treatment for $1 \mathrm{~h}$ at $650{ }^{\circ} \mathrm{C}$, and, finally, by re-aging for $1 \mathrm{~h}$ at $780^{\circ} \mathrm{C}$.

Acknowledgments: This work was financially supported by the National Natural Science Foundation of China (Grant No. 51504019 and No. 51374022).

Author Contributions: Yi Zhang and Jing Li conceived and designed the experiments; Yi Zhang and Yong-Feng Qi performed the experiments; Yi Zhang and Cheng-Bin Shi analyzed the data; Cheng-Bin Shi and Qin-Tian Zhu were responsible for language modification; Jing Li contributed reagents/materials/analysis tools; Yi Zhang wrote the paper.

Conflicts of Interest: The authors declare no conflict of interest.

\section{References}

1. Norström, L.Å.; Öhrberg, N. Development of hot-work tool steel for high-temperature applications. Metals Technol. 2013, 8, 22-26. [CrossRef]

2. Kremnev, L.S.; Brostrem, V.A. Heat resistance of tool steels and alloys. Metal Sci. Heat Treat. 1973, 15, 225-230. [CrossRef]

3. Grabovskii, V.Y.; Kanyuka, V.I. Austenitic Die Steels and Alloys for Hot Deformation of Metals. Metal Sci. Heat Treat. 2001, 43, 402-405. [CrossRef]

4. Adrian, H. Thermodynamic model for precipitation of carbonitrides in high strength low alloy steels containing up to three microalloying elements with or without additions of aluminium. Mater. Sci. Technol. 1992, 8, 406-420. [CrossRef]

5. Li, J.; Huang, H.Y. High Nitrogen Steels and Stainless Steels: Manufacturing, Properties and Applications; Chemical Industry Press: Beijing, China, 2006.

6. Stein, G.; Hucklenbroich, I. Manufacturing and Applications of High Nitrogen Steels. Mater. Manuf. Process. 2006, 19, 7-17. [CrossRef]

7. Rashev, T. Development of Laboratory and Industrial Installations for One Stage Production of HNS. Mater. Manuf. Process. 2004, 19, 31-40. [CrossRef]

8. Li, J.Y.; Zhao, P.; Yanagimoto, J. Effects of heat treatment on the microstructures and mechanical properties of a new type of nitrogen-containing die steel. Int. J. Miner. Metall. Mater. 2012, 19, 511-517. [CrossRef]

9. Li, J.Y.; Chen, Y.L.; Huo, J.H. Mechanism of improvement on strength and toughness of H13 die steel by nitrogen. Mater. Sci. Eng. A. 2015, 640, 16-23. [CrossRef]

10. Jiang, H.; Wu, X.C.; Shi, N.N. Effects of nitrogen on microstructure and properties of austenitic hot work die steel. Mater. Mech. Eng. 2012, 36, 58-61.

11. Zhang, Z.Y.; Rong, J.K. A study of austenitic hot work die steel. CISRIC Tech. Bull. 1985, 5, 47-53.

12. ASTM E 112-10. Standard Methods for Estimating the Average Grain Size; ASTM International: West Conshohocken, PA, USA, 2010.

13. SISC IAS V8.0. Scientific Instrument Software Corporation Limited: Beijing, China, 2003.

14. ASTM A370. Standard Test Methods and Definitions for Mechanical Testing of Steel Products; ASTM International: West Conshohocken, PA, USA, 2010.

15. Lee, S.J.; Lee, Y.K. Prediction of austenite grain growth during austenitization of low alloy steels. Mater. Des. 2008, 29, 1840-1844. [CrossRef]

16. Han, L.Z.; Chen, R.K.; Gu, J.F.; Pan, J.S. Behavior of austenite grain growth in X12CrMoWVNbN10-1-1 ferrite heat-resistant steel. Acta Metall. Sin. 2009, 45, 1446-1450. 
17. Kurtz, S.K.; Carpay, F.M.A. Microstructure and normal grain growth in metals and ceramics. Part I. Theory. J. Appl. Phys. 1980, 51, 5725-5744. [CrossRef]

18. Staśko, R.; Adrian, H.; Adrian, A. Effect of nitrogen and vanadium on austenite grain growth kinetics of a low alloy steel. Mater. Charact. 2006, 56, 340-347. [CrossRef]

19. Speer, J.G.; Michael, J.R.; Hansen, S.S. Carbonitride precipitation in niobium/vanadium microalloyed steels. Metall. Mater. Trans. A 1987, 18, 211-222. [CrossRef]

20. Matsuo, S.; Ando, T.; Grant, N.J. Grain refinement and stabilization in spray-formed AISI 1020 steel. Mater. Sci. Eng. A 2000, 288, 34-41. [CrossRef]

21. Adamczyk, J.; Kalinowska-Ozgowicz, E.; Ozgowicz, W.; Wusatowski, R. Interaction of carbonitrides V(C,N) undissolved in austenite on the structure and mechanical properties of microalloyed V-N steels. J. Mater. Process. Technol. 1995, 53, 23-32. [CrossRef]

22. Humphreys, F.J.; Hatherly, M. Chapter 6-Recovery after Deformation. Recrystallization E Related Annealing Phenomena; Elsevier Limited: Amsterdam, The Netherlands, 2004; pp. 169-213.

23. Dutra, J.C.; Siciliano, F., Jr.; Padilha, A.F. Interaction between Second-Phase Particle Dissolution and Abnormal Grain Growth in an Austenitic Stainless Steel. Mater. Res. 2002, 5, 379-384. [CrossRef]

24. Abbaschian, R.; Reedhill, R.E. Physical Metallurgy Principles, 4th ed.; Cengage Learning: Stamford, CT, USA, 2009.

25. Lanskaya, K.A. High-Temperature Steels [in Russian]; Metallurgiya: Moscow, Russia, 1969.

26. Werenskiold, J.C.; Deschamps, A.; Bréchet, Y. Characterization and modeling of precipitation kinetics in an Al-Zn-Mg alloy. Mater. Sci. Eng. A 2000, 293, 267-274. [CrossRef]

27. Yang, R.X.; Liu, Z.Y.; Ying, P.Y.; Li, J.L.; Lin, L.H.; Zeng, S.M. Multistage-aging process effect on formation of GP zones and mechanical properties in Al-Zn-Mg-Cu alloy. TNMSC 2016, 26, 1183-1190. [CrossRef]

28. NADCA Die Material Committee. NADCA Recommended Procedures for H13 Tool Steel; NADCA \#207-2003; North America Die Casting Association: Arlington Heights, IL, USA, 2003.

29. Yan, P.; Liu, Z.; Bao, H.; Weng, Y.; Liu, W. Effect of tempering temperature on the toughness of 9Cr-3W-3Co martensitic heat resistant steel. Mater. Des. 2014, 54, 874-879. [CrossRef]

30. Gao, J.M. Mechanical Properties of Materials, 1st ed.; Wuhan University of Technology Press: Wuhan, China, 2004. (In Chinese)

(C) 2017 by the authors. Licensee MDPI, Basel, Switzerland. This article is an open access article distributed under the terms and conditions of the Creative Commons Attribution (CC BY) license (http:/ / creativecommons.org/licenses/by/4.0/). 